\title{
Towards an Afrocentric approach to
}

\section{psychiatry}

Dan Lamla Mkize is Professor and Head: Department of Psychiatry, Clinic al Head:

KwaZulu-Natal Mental Health Services, and Task Team Leader: Afric an Health Ca re Systems Initiative, Nelson R Mandela School of Medic ine, Durban.

'People have sought comfort for their miseries and a cure for their tro ubles since prehistoric time'. (Sharon Romm, 1994')

\section{Int ernational psychiatry}

International psychiatry has its roots in Anglo-European societies of the 19 th century. Ideas and methods on mental health and illness grew out of the modern concept of disease that had consolidated in the early modern period. During the course of the 19 th century and into the 20 th century a medical, organic approach to mental illness evolved. Alienists from various Anglo-European societies proceeded to communicate and exchange ideas about their findings and managed to develop a suitable language for description and analysis that would be applicable across national boundaries. International psychiatry then consolidated during the mid20 th century as the analytical calculus and descriptive lexicon gained precision, reliability, validity, general clinical applicability, and social acceptability. The result was the creation of an international system of diagnosis and classification in a common language of nosology that could be applied in an effective way across national boundaries. ${ }^{2}$

\section{Cult ural psychiatry}

Cultural psychiatry was born out of the realisation that a measure of ethnocentrism pervades scientific and especially international psychiatry and entails an active challenge to its universalism. Its goal was to demonstrate thatas a function of culture there were differences attending the pursuit of typical clinical ta sks of psychiatry. These were not just the ma lfunction of specific chemical systems or lesions of a natomically discrete brain regions associated with psychiatric disorders. Instead, what was also needed to understand them properly was their social and cultural content The latter required giving attention to how communities defined, understood, interpreted, valued, and realised their respective values and tradi-

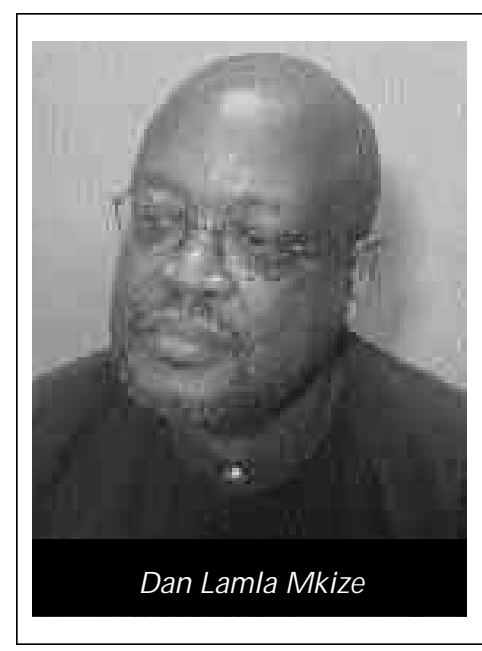

tions in personal experience and symbolic behaviour. It was in relation to such locally shaped cultural psychologies and cultural constructions of the body and personhood that problems of mental health and illness acquired meaning and form. ${ }^{2}$

The relation between culture and mental illness has changed significantly over the last 100 years. At the beginning of the last century cultural psychiatry was la rgely concerned with the description of exotic features of clinical syndromes found in Africa and other non-W estern locations. Today cultural psychia try is concerned with interviews a cross the cultural ba rrier, communication skills, cultural formulation, cultural identity, effects of acculturation, culturally specific therapies, ethnopsychopharmacology, pharmacogenetics and environmental factors. ${ }^{3}$

\section{African psychiat ry}

Psychiatry has its roots not only in biological medicine but also in behavioural science. It cannot be divorced from the history of the 
society in which it is practised, and histo rically most African countries differ widely from $\mathrm{N}$ orth America and $\mathrm{W}$ estern Europe. Yet psychiatric teaching and practice are based on the experience of $W$ estern societies, which may not be applicable to Africa. To be effective, psychiatry must fit the African cultural pattern. ${ }^{4}$

South Africa is a multicultural society with a predominant A frican culture. To have a clear understanding of the African view of the mental illness, one must have a clear view of the African concept of the causes of mental illness. Although it is not possible to speak of a single African viewpoint, the different cultures south of the Sahara do share a consciousness of the world and an inventory and structure of tenets about it ${ }^{5}$ The African view of mental ill health currently encompasses a wide spectrum - from ancestors, folk belief in witchcraft, to modern medical science. All the systems function simultaneously with the African culture and within the individual and easily fit and complement one another. This view also fits well into the biopsychosocial model. The problem for a long time has been the inability to bring the $W$ estern and traditional healing systems together. In traditional African cultures mental illness is integrated into social order and cosmic order. Each member of the culture has precise conceptual and operational models for the causes of the mental illness.

In African medicine the sick a re treated or cared for in a particular way in terms of traditional African thinking, which is claimed as being different from $W$ estern thinking. A very important reason for this is that the African view of what a human being is differs from other views, especially from the so-called $W$ estern view. A view of what a human being is has wide implications for how people are treated in different life situations, e.g. students, employees, subordinates, brothers and sisters, parents, children, and sick people. To treat people in a certain way in any specific situation implies a universal way of thinking with regard to what a human being is. This universal way of thinking may be termed a world view, a way of life, frame of reference, conceptual scheme, web of beliefs or view of life. ${ }^{5}$

Care of the mentally ill in Africa has for centuries been in the hands of traditional and religious healers. M ental health has alw ays been a part of general medical care; the concept of physical and psychological dualism is alien to Africa. W ith the introduction of hospital care, litte has been done to integrate and refine indigenous resources. In many African countries the medical services are limit ed and poor. Some or most of them cannot afford to provide adequate mental health care, yet there has been little attempt to operate efficiently and with imagination using the restricted services that they can provide. The nature of psychopathological phenomena in these changing societies is not given enough weight in designing and operating national programmes of prevention and treatment of mental ill health. W estern models are copied. Psychological theories based on European civilisation are imposed on unrelated societies. ${ }^{4}$

Most physical illnesses can be dealt with fairly satisfactorily, regardless of the culture of patient and doctor. This is not true of mental illness. Psychiatry is crucially informed by culture and other social, biological and psychological factors and processes. Cultures differ regarding their definition of health, ill health and healing. W estern psychiatry now has much to offer to the African patient, but there are serious obstacles in the way. The chief obstacle is a fundamental difference in social and cultural background between doctor and patient. ${ }^{6}$

\section{African psychotherapy}

All traditional types of psychotherapy must obviously reflect local beliefs regarding human nature, and in many cultures this means that the close links between individuals, their ancestors, and the spirit world play a prominent role in treatment Healing is based on the establishment and maintenance of satisfactory relationships between these different elements - the present, the past, and the spirit world. The patient, therefore, does not consider the 'illness' as something to be cured or controlled but as something to be understood and acknowledged. ${ }^{6}$ It is no longer a matter of explaining the mechanisms in order to control them, but of understanding a significance, a meaning. The question is not how but why things happen. To understand the meaning of the illness or of the symptoms introduces a further dimension into the relationship between the patient and those around him, and between the patient and those treating him. This concept goes much further than the Freudian psychoanalytical theory of symptoms as symbolic representations.

Psychoanalysis, like the rest of modern medicine, is centred on the concept of a failure of certain mechanisms within the individual. To the psychoanalyst these mechanisms are inherent in the patient's personality, which in its turn reflects his history and in particular his childhood. For the African therapist, on the other hand, the symptoms a re manifestations of a conflict betw een the patient and other individuals, dead or alive, spirits and the non-material forces that pervade society. His first task is to grasp the social meaning of the symptoms. Knowing the patient's culture he is able to say, for example, 'You have broken the taboos of your family and thus offended your ancestors; that is why you are ill.' The patient and his relatives must therefore try to understand the illness. It is the message of the illness that is feared, not the patient himself. How ever disturbed he may be, the patient is not excluded or rejected. $\mathrm{He}$ is listened to and considered as a human being in the full sense. The illness is everybody's business; the family and the community are just as concerned as the victim who bears the message. ${ }^{7}$

\section{Therapeut ic community}

The concept of a therapeutic community as a treatment strategy in psychiatry has a sizeable body of literature and was brought back into prominence in the $1950 \mathrm{~s}$. Despite similar objectives, concepts about the physical setup and the working of a therapeutic commu- 
nity differ, and so do definitions in the literature. In the W est, specifically in mental health institutions, the definition of therapeutic community may include only patients from the same ward or selected others. In Africa, it tends to be more inclusive and larger, sometimes involving a chain of villages. ${ }^{8}$

A therapeutic community is defined in terms of collaborative efforts between the therapist or medical practitioner and the patients. The term implies that the responsibility for treatment is not confined to the trained medical staff but is a concern also of the other community members and patients. Implied in this definition is that the hospital is a therapeutic community. From a wider perspective, the therapeutic community is a social structure with its own particular ways and laws, and is not to be confused with a setting in which one has freedom to do as one pleases without restriction. It has conscious design, and its main aim is to help the patient become a more mature and rational person, not merely as well as he once was. ${ }^{8}$

Four therapeutic ideologies and principles guide the establishment of therapeutic communities: rehabilitation, permissiveness, democratisation, and communalism.

Briefly, rehabilitation implies normalising the patient to the total enviro nment through the community assuming the dual functions of a treatment medium, and of representing the individual's microcosm in which he is faced with the reality, as much as possible, of life events. Permissiveness enjoins all the community members, patients, and staff to be tolerant of the distressful behaviour of the pathological members. Ideally, this should allow the pathological individual to demonstrate his difficulties and the community members to examine the basis for their own reactions.

According to the concept of democratisation, a 'blurring of role differences' is encouraged insofar as chaos is kept in check through every member of the community having to make responsible and constructive contributions. Communalism involves a broadly based social interaction and commonality of purpose for the mutual benefit of all members of the therapeutic community. Such a communal atmosphere is expected to engender sharing, informality, social connectedness, and freeing of communication to give patients the feeling of being included and belonging to the system. In some African communities where the equilibrium ot the traditional life pattern is still relatively undisturbed these four basic elements of a therapeutic community are a natural part of the community network and only aw ait a systematic rechannelling toward therapeutic ends. ${ }^{9}$

The best example of a therapeutic community is the $\mathrm{N}$ igerian Aro village treatment centre, founded by Lambo. The approach is rooted in the village system that permits trea tment of the mentally ill utilising inherent dynamic resources of the social environment as the principal therapeutic technique. It is a salutary blend of indigenous African psychotherapy and $W$ estern psychotherapy and medication. Patients who are admitted for treatment must be accompanied by a predetermined number of close relatives. In addition to medication, social activities geared tow ards normalisation of patients include watching movies, cultural activities, social dancing, church services and so on. In this way a smooth biological, psychological and social normalisation occurs, with a low rate of illness recidivism and readmission. Similar programmes are reported to have begun in $G$ hana and a number of other A frican countries. ${ }^{8}$

Emerging from this culture-community orientation in psychotherapy is an active intellectual movement a mong A frican psychiatrists and other practitioners in medicine and allied health professions calling for the integration of the traditional and $W$ estern modes of treatment. Several investigators found that psychiatric patients usually consulted traditional African doctors before coming to the W estern treatment centres and mental hospitals. In fact, some managed to receive treatment from both mental hospitals and traditional African healers, even if this meant using a pseudonym to falsify records and various other deceptions. ${ }^{8}$

Some African countries have recognised indigenous healers and, in some cases have accorded them equal status with $W$ esterntrained medical practitioners. South Africa is in the process of acknowledging the important role of the African health care system and the role indigenous healers can play.

\section{Int ergrating Western and African psychiat ry}

It is often believed that the view of modern psychiatry and psychotherapy is logical, while that of traditional therapies is pala eological. It is forgotten that both modes of thinking a re prevalent in both settings. Again, the rationale of $W$ estern psychotherapy resembles the rationale of primitive therapies in that it is not subject to disproof - it cannot be shaken by therapeutic failure. ${ }^{1}$ It may not be possible to assert which view is more valid. To say that a certain neurotic behaviour is due to mental conflict or that a disturbed behaviour is due to an evil spirit is not saying anything very different $\mathrm{N}$ eurotic has approximately the same meaning as disturbed, and a conflict may be construed as an evil spirit of some kind. If this is realised and no attempt is made at proselytising, therapy can progress smoothly. It must be realised that the two world views are not antithetical but complementary; one answers the how, and the other the why and the who behind the malady. The two view s may well coexist and operate within selective contexts. ${ }^{10}$

G illian Straber, ${ }^{11}$ a psychologist working in Johannesburg, reports how an integration of African and $W$ estern healing methods helped to treat three young sisters suffering from post-traumatic stress disorder. Through a detailed analysis of a dream shared by the three adolescent girls, she outlined many similarities between an African and a $W$ estern understanding of their symptoms. She demonstrates how both systems acknow ledge the symptoms to be a function of the breaching of stimulus boundaries, the existence 
of survivor guilt and the phenomenon of frozen mourning. She illustrates further how many factors considered part of W estern psychotherapy are applicable to psychotherapy with African patients, for example catharsis following an emotional reliving of the trauma, re-ordering of perceptions following insight, and fostering hope for the future.

In South A frica psychiatric practice is mainly of the $W$ estern type. This is not unexpected as the majority of psychiatrists are white. There are about 20 African psychiatrists, all of them trained in W estern psychiatry. These few African psychiatrists should advocate an Afrocentric approach to psychiatry based on a blending and integration of all facets of knowledge of the behavioural sciences, biology, ethnopharmacology, genetics, sociology and anthropology. The best psychiatry possible provides expert scientific diagnosis and therapy in the light of an appreciation of the role played by cultural factors in shaping human behaviour. African psychiatry should inform the government and society about human behaviour and societal response to a transition from oppression to freedom and to the HIV/ AIDS pandemic. It must have explanations for the high prevalence of crime, murder and child rape. W e need scientists qualified in the mental health field to conduct field research into the aspects of A frican culture that impinge on the prevention, diagnosis and treatment of mental illnesss.

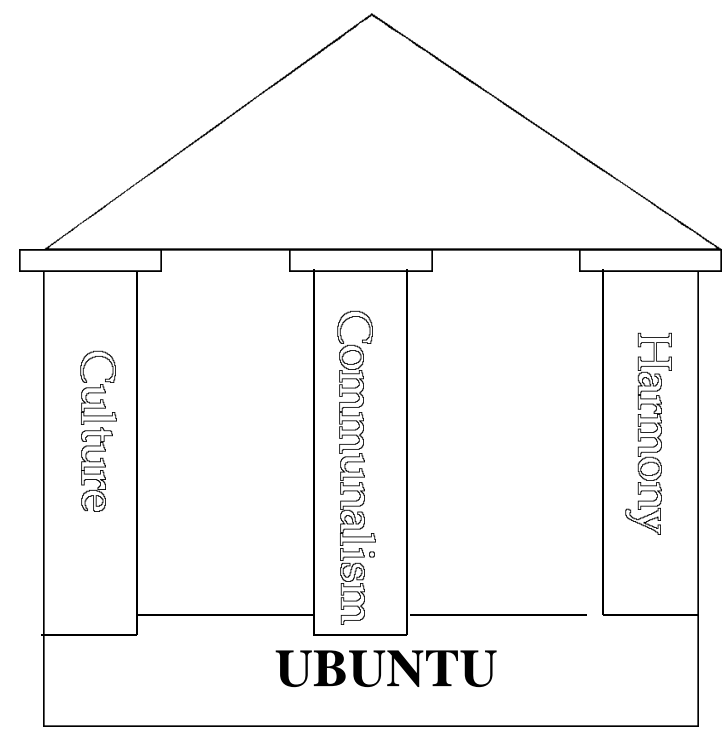

\section{The way forward}

Having considered the history of psychiatry, the challenge is to develop a system that incorporates both approaches. This system should be based on the core African cultural value of Ubuntu.

Besides the four therapeutic ideologies that guide the establishment of therapeutic communities, African psychiatry should have a strong foundation of Ubuntu, with three pillars of Culture,
Harmony and Communalism. Ubuntu involves sensitivity to the needs and wants of others, sharing, and being sympathetic, caring, considerate, patient and kind. It means qualities such as warmth, empathy, understanding, communication, interaction, participation, reciprocation, harmony, a shared world view and co-operation. ${ }^{11}$

\section{Cult ure - a key concept for psychiat ry}

C ulture refers to meanings, values and behavioural norms that are learned and transmitted in the dominant society and within its social groups. Culture powerfully influences cognition, feelings, and self-concept as well as the diagnostic process and treatment decisions. Culture is therefore best conceptualised as a to tality, composed of a complex system of symbols with subjective dimensions such as values, feelings, and ideals, and objective dimensions including beliefs, traditions, and behavioural prescriptions, articula ted into laws and rituals. This unique capacity of culture to bind the objective world of perceived reality to the subjective world of the personal and intimate lends it its powerful role as expressor, mediator, and moderator of psychological processes and, ultimately, emotional disorders. ${ }^{3}$

The concept of communalism has been discussed above.

An individual needs to be in harmony with self, family, community, environment and the universe. This concept is similar to the biopsychosocial approach. M ental illness is an indication of the disharmony in one or more of the above areas.

\section{L Mkize}

Department of Psychiatry

$\mathrm{N}$ elson R M andela School of M edicine

University of $\mathrm{N}$ atal

Durban

1. Romm S. A sketch of man's efforts to mend his troubled mind. Psychiatric Clinics of North America 1994; 17: $453-469$.

2. Fabrega H. Epilogue. Psychia tric Clinics of $\mathrm{N}$ orth America 2001; 3: $595-607$

3. Trujillo M. Cultural psychiatry. In: Kaplan HI, Sadock BJ, eds. Comprehensive Textb ook of Psychiatry. Vol 11. 6th ed. Ba ltimore: W illiams and W ilkins 1995 : 492-499.

4. Lambo TA. Psychiatry in the tropics. Lancet $1965: 2: 1119-1121$.

5. N eki JS, Joinet BM, Hogan M, Hauli TG, Kilonzo G. The cultural perspective of therapeutic relationship - a view point from A frica. Acta Psychiatr Scand 1985 71: $543-550$

6. Psychiatry for Africa, (Editorial) S Afr M ed I 1979: 55: 149-150.

7. Harding TW. Traditional healing methods for mental disorders. W HO Chronicle 1975; 31: $437-440$

8. Jones M. The concept of a therapeutic community. Am J Psychia try 1956; 1: 647 . 650 .

9. Awanbor D. The healing process in African psychoathera py. Am J Psychother 1982 36: $206-213$.

10. Straber $G$. Integrating Afric an and W estern hea ling practices in South Africa. Am Psychother 1994; 48: 455-467.

11. Prinsloo ED. A comparison between medicine from an A frican (Ubuntu) and $W$ estern philosophy. Curationis 2001; 24: 58-65. 